\title{
PENGARUH SAFETY TRAINING TERHADAP KETRAMPILAN ORANG TUA DALAM PENANGANAN CEDERA BALITA DI PMB BIDAN I KABUPATEN BANDUNG
}

\author{
Dian Purnama Sari ${ }^{1)}$, Retna Hermawati ${ }^{2)}$ \\ ${ }^{1}$ Dosen Sarjana dan Profesi Kebidanan STIKes Dharma Husada Bandung \\ ${ }^{2}$ Mahasiswa Diploma Tiga Kebidanan STIKs Dharma Husada Bandung \\ dians1552@gmail.com
}

\begin{abstract}
ABSTRAK
Salah satu masalah yang sering terjadi pada masa anak-anak adalah kecelakaan atau cedera. Cedera termasuk salah satu dari beberapa penyebab utama morbiditas dan mortalitas anak di dunia. Tindakan pencegahan cedera berupa pengawasan yang dapat dilakukan oleh orang tua, karena dalam beraktivitas anak tidak memperhatikan bahaya. Safety training sebagai kegiatan yang menjamin terciptanya kondisi yang aman, terhindar dari gangguan fisik dan mental melalui pembinaan dan pelatihan, pengarahan, dan kontrol terhadap pelaksanaan kegiatan yang dapat di lakukan oleh orang tua. Penelitian ini menggunakan quasy experimental study with control group design. Sample didapatkan dengan menggunakan simple random sampling yaitu orang tua. Penelitian ini dilaksanakan pada bulan April 2021. Cara pengumpulan data penelitian dengan menggunakan ceklist. Uji statistik dalam penelitian ini menggunakan Paired T-Test dan Independent T-Test. Hasil penelitian menunjukkan bahwa pengaruh safety training terhadap keterampilan orang tua dalam penanganan cedera balita di rumah tangga dengan uji PairedT-Test hasil pre-test dan post-test pada kelompok intervensi $\mathrm{p}=0,001$ $(\mathrm{p}<0,05)$, sedangkan hasil pre-test dan post-test pada kelompok kontrol $\mathrm{p}=0,568$. Uji Independent $\mathrm{T}$ Test pada kelompok intervensi dan kontrol mendapat hasil pre-test $p=0,337(p>0,05)$ dan hasil posttest $p=0,001(p<0,05)$. Pengasuhan anak dilakukan sepenuhnya oleh orang tua, karena pada masa ini seorang anak lebih banyak dilewatkan dalam lingkungan keluarga.
\end{abstract}

\section{Kata kunci : Safety training, Cedera, Keterampilan, Balita.}

\section{PENDAHULUAN}

Seorang anak usia toddler (1-3 tahun) menunjukkan perkembangan motorik yang lebih lanjut dan anak menunjukkan kemampuan aktivitas yang lebih banyak bergerak, mengembangkan rasa ingin tahu dan eksplorasi terhadap benda-benda yang ada disekelilingnya (Harnowo, 2013). Keterampilan motorik seperti berlari, berjalan, melompat menjadi sangat luwes, tetapi otot dan tulang belum begitu sempurna. Melihat karakteristik perkembangannya, anak usia toddler lebih berisiko terjadi kecelakaan (Kuschitha, 2007).
Cedera merupakan ancaman bagi kesehatan diseluruh dunia. Menurut World Health Organization (WHO) dalam Indarwati \& Ratna Dewi cedera mengakibatkan 5,8 juta kematian di seluruh dunia, dan lebih dari 3 juta kematian diantaranya terjadi di negara-negara berkembang (Aken, 2007). Berdasarkan penelitian Kuschithawati, cedera mengakibatkan $7 \%$ kematian diseluruh dunia dan angka ini masih terus bertambah (Mulyanti, 2015). World Health Organization (WHO) menyebutkan bahwa cedera yang disengaja dan tidak disengaja menyebabkan 42\% kematian anak usia 1-4 tahun di Asia. 
JURNAL SEHAT MASADA VOLUME XVI

Keseluruhan rata-rata cedera pada anak usia 0-

3 tahun per tahunnya yaitu sebanyak 371/100.000 anak (Dempsey, 2002).

Upaya pencegahan yang dapat dilakukam dalam kasus cedera pada balita adalah dengan cara memberikan pendidikan kesehatan untuk meningkatkan pengetahuan dan keterampilan safety (keamanan) (Magfuri, 2014). Pendidikan kesehatan adalah adalah proses yang direncanakan dengan sadar untuk menciptakan peluang bagi individu-individu untuk senantiasa belajar memperbaiki kesadaran (literacy) serta meningkatkan pengetahuan danketerampilannya (life skills) demi kepentingan kesehatannya. Pendidikan kesehatan tidak hanya memberikan informasi saja, tetapi yang penting adalah menciptakan kegiatan yang dapat memandirikan seseorang untuk mengambil keputusan terhadap kesehatan yang dihadapi (Wahyu, 2009).

\section{METODE PENELITIAN}

Penelitian ini menggunakan metode cross sectional. Dalam desain penelitian ini, diuji pengaruh safety training terhadap ketrampilan orang tua dalam penanganan cedera balita. Populasi dalam penelitian ini adalah semua orang tua balita yang berkunjung di PMB BIDAN I Kabupaten Bandung yang tercatat lengkap di dalam data rekam medis pada bulan April dan Mei 2021.

\section{HASIL DAN PEMBAHASAN}

A. HASIL

Tabel 1 Karakteristik Responden Penelitian $(\mathrm{N}=42)$

\begin{tabular}{lcc}
\hline \multicolumn{1}{c}{ Variable } & $\boldsymbol{F}$ & $\boldsymbol{\%}$ \\
\hline Usia & & \\
25-35 tahun & 21 & 50.0 \\
36-45 tahun & 21 & 50.0 \\
\hline Total & 42 & 100.0 \\
\hline Pekerjaan & & \\
$\quad$ Wiraswasta & 14 & 32.4 \\
ASN & 12 & 29,0 \\
Ibu rumah tangga & 10 & 23,5 \\
Karyawan & 6 & 14,7 \\
\hline Total & 42 & 100,0 \\
\hline Pengalaman Penanganan & & \\
$\quad$ Pernah & 28 & 67.6 \\
Belum pernah & 14 & 32.4 \\
\hline Total & 42 & 100.0 \\
\hline Sumber : Data Primer Tahun 2021 &
\end{tabular}

Berdasarkan pada tabel 1, karakteristik responden berdasarkan jenis usia, yaitu rentang usia 25-35 tahun terdapat 21 orang $(50,0 \%)$, dan usia 36-45 tahun terdapat 21 orang $(50,0 \%)$.

Karakteristik responden berdasarkan jenis pekerjaan yaitu Wiraswasta 14 orang $(32,4 \%)$, PNS 12 orang $(29,4 \%)$, Ibu rumah tangga 10 orang $(23,5 \%)$, karyawan 6 orang $(14,7 \%)$.

Karakteristik responden berdasarkan pengalaman menangani cedera balita yaitu 28 responden $(67,6 \%)$ pernah menangani cedera balita, 14 responden $(32,4 \%)$ belum pernah menangani cedera balita. 
JURNAL SEHAT MASADA VOLUME XVI

Tabel 2 Perbedaan nilai pre-test dan post-test pada kelompok intervensi dan kelompok kontrol

\begin{tabular}{lrrr}
\hline \multicolumn{1}{c}{ Variable } & \multicolumn{3}{c}{ Tingkat Keterampilan } \\
Mean & SD & P \\
\hline Kelompok Intervensi & & & \\
Pretes & 23,94 & 7,830 & 0,001 \\
Postes & 40,71 & 3,442 & \\
\hline Kelompok Kontrol & & & \\
Pretes & 21,53 & 6,530 & 0,568 \\
Postes & 21,88 & 5,797 & \\
\hline \multicolumn{2}{l}{ Sumber : Data primer (2021) }
\end{tabular}

NOMOR 1 Januari 2022

ISSN : 1979-234

Berdasarkan tabel 2, didapatkan hasil bahwa kelompok intervensi nilai $\mathrm{p}=0,001$, karena $\mathrm{p}<0,05$ berarti terdapat perbedaan pengaruh tingkat pengetahuan penanganan cidera balita pada kelompok intervensi. Sedangkan untuk kelompok kontrol nilai $p=0,568$, karena $p>0,05$ berarti tidak terdapat perbedaan antara pre-test dan post-test.

Tabel 3. Perbedaan tingkat keterampilan antara kelompok control dan kelompok intervensi sebelum dan sesudah diberikan safety training

\begin{tabular}{lcccc}
\hline \multicolumn{1}{c}{ Variable } & \multicolumn{2}{c}{ Tingkat Keterampilan } & P & Pean \\
& $\boldsymbol{N}$ & & & \\
\hline Pretest & 17 & 23,94 & 23,94 & 0,337 \\
Kelompok intervensi & 17 & 21,52 & 21,52 & \\
Kelompok Kontrol & & & & \\
\hline Postes & 17 & 40,70 & 3,441 & 0,001 \\
Kelompok intervensi & 17 & 21,88 & 5,797 & \\
Kelompok Kontrol & & & & \\
\hline
\end{tabular}

Berdasarkan tabel 3 didapatkan hasil kelompok pre-test pada kelompok intervensi dan kelompok control nilai $\mathrm{p}=0,337$, karena nilai $\mathrm{p}>0,05$ berarti tidak terdapat pengaruh pada pre-test kelompok intervensi dan kelompok kontrol. Sedangkan pada post-test kelompok intervensi dan kelompok kontrol didapatkan hasil $\mathrm{p}=0,001$, karena nilai $\mathrm{p}<0,05$ terdapat perbedaan antara hasil post-test kelompok intervensi dan post-test kelompok kontrol berarti ada pengaruh safety training dalam penanganan cidera pada balita.

\section{B. PEMBAHASAN}

Ada perbedaan keterampilan antara pretest dan post-test pada kelompok intervensi, sedangkan hasil pada kelompok kontrol saat pre-test dan post-testtidak ada perbedaan hasil. Hal tersebut terjadi karena pada kelompok intervensi diberikan pendidikan safety training. Hasil penelitian ini menunjukkan terdapat pengaruh safety training terhadap keterampilan orang tua dalam menghadapi cidera balita. Hal ini sejalan dengan penelitian yang dilakukanVranada A pengetahuan orang tua dalam pencegahan kecelakaan anak usia toddler dipengaruhi oleh beberapa faktor diantaranya adalah pendidikan, pengalaman terhadap suatu kejadian dan fasilitas. Pengalaman orang tua di Caturbinangun dalam menangani kecelakaan balita cukup tinggi dari 5 orang tua terdapat 4 orang tua yang anaknya pernah cedera. Surbakti menyebutkan bahwa pengalaman dapat diartikan juga sebagai memori episodik, yaitu memori yang menerima dan menyimpan peristiwa yang terjadi atau dialami individu pada waktu dan 
tempat tertentu, yang berfungsi sebagai referensi otobiografi.

Dari posyandu yang dilakukan rutin sebulan sekali juga belum pernah mengadakan penyuluhan ataupun pelatihan tentang safety training kepada orangtua terhadap cedera balita. Hal ini tidak sejalan dengan penelitian Yuli yaitu Safety training sebagai kegiatan yang menjamin terciptanya kondisi yang aman, terhindar dari gangguan fisik dan mental melalui pembinaan dan pelatihan, pengarahan, dan control terhadap pelaksanaan kegiatan. Menurut Notoatmodjo pelatihan keselamatan merupakan upaya preventif yang kegiatan utamanya adalah identifikasi, substitusi, eliminasi, evaluasi, dan pengendalian risiko dan bahaya.

Terkait dengan fasilitas yang menunjang penanganan cedera balita di rumah tangga kurang mendukung dikarenakan di setiap rumah belum semuanya mempunyai kotak obat. Sehingga faktor sarana akan menjadikan suasana kerja menjadi lebih optimal yang tentunya akan lebih mendukung keterampilan seseorang dalam melakukan suatu tindakan. Keterampilan tidak akan dapat dicapai bila mana tidak didukung dengan sarana yang memadai sesuai dengan apa yang diinginkan, karena sarana merupakan bagian dari proses untuk menjadikan seseorang menjadi terampil. Ismaryati dalam Syahputra menyebutkan bahwa fasilitas merupakan segala sesuatu yang dapat memudahkan dan memperlancar pelaksanaan suatu usaha dapat berupa bendabenda maupun uang. Jadi, dalam hal ini fasilitas dapat disamakan dengan sarana yang Jurnal Penelitian Kesehatan STIKes Dharma Husada Bandung 
Alimul Hidayat,A. Aziz. (2005). Pengantar ilmu keperawatan anak 1. Jakarta: Salemba Medika.

Arikunto, Suharsimi. 2003. Prosedur Penelitian, Suatu Praktek. Jakarta:Bina Aksara. Arikunto, Suharsimi. 2006. Prosedur Penelitian. Jakarta: PT Rineka Cipta.

Arikunto. 2002. Metodologi Penelitian Suatu Pendekatan Proposal. Jakarta : PT. Rineka Cipta.

Badan Penelitian dan Pengembangan Kesehatan. 2013. Riset Kesehatan Dasar 2013. Jakarta: Kementrian Kesehatan RI.

Dahlan, M. Sopiyudin, 2010. Besar Sampel dan Cara Pengambilan Sampel. Jakarta: Salemba Medika.

Dempsey, P.A., \& Demppsey, A.D. (2002). Riset Keperawatan : Buku ajar danlatihan ( Alih bahasa oleh Budi, E \& Rika, I) Edisi 4. Jakarta : EGC.

Depkes RI. 2010. Penuntun Hidup Sehat. Edisi Keempat, Jakarta.
Dessler Gary, 2009. Manajemen Sumber Daya Manusia, Jakarta :Edisi Kesepuluh Jilid Dua PT Indeks halaman 46.

Harnowo, Putro Agus. 2013. P3K: Pertolongan Pertama dan Penanganan Darurat. Itokindo.

Hasanah, K. 2011. Tingkat Pengetahuan Siswa Tentang Kesehatan Dan Keselamatan Nursalam. 2013. Pendekatan Praktis Metodologi Penelitian Ilmu Keperawatan. Jakarta: Salemba Medika.

Polit, D.F., Beck, C.T. (2012). Nursing research: generating and assesing evidance for nursing practice 9th edititon. Philadelphia: Lippincott Wiliams \& Walkins.

Ratnaningrum, Wuriani. 2009. Pengaruh Pendidikan Kesehatan Tentang Save The Children Terhadap Pengetahuan Dan Perilaku Orang Tua Dalam Pencegahan Kecelakaan Pada Balita. Karya Tulis Ilmiah. Universitas Muhammadiyah Yogyakarta: Yogyakarta. 